\title{
The Role of Nuclear Power from a System Engineering Standpoint
}

\author{
Luciano Ondir Freire, Delvonei Alves de Andrade \\ Nuclear and Energy Research Institute, Instituto de Pesquisas Energéticas e Nucleares, São Paulo, Brazil \\ Email: luciano.ondir@gmail.com
}

How to cite this paper: Freire, L.O. and de Andrade, D.A. (2017) The Role of Nuclear Power from a System Engineering Standpoint. World Journal of Nuclear Science and Technology, 7, 167-188. https://doi.org/10.4236/wjnst.2017.73015

Received: May 30, 2017

Accepted: July 1, 2017

Published: July 4, 2017

Copyright $\odot 2017$ by authors and Scientific Research Publishing Inc. This work is licensed under the Creative Commons Attribution International License (CC BY 4.0).

http://creativecommons.org/licenses/by/4.0/

(c) (i) Open Access

\begin{abstract}
This work proposed the application of system engineering methods to identify organizations vital for society, seeking development and well-being. System engineering requires the identification of blocks (or systems), identification of their service functions, identification of states, identification of required quality and identification of constraints. Analyzing modern societies, vital functions were identified and countries behavior was modeled, identifying their states. In this context, nuclear power was found to be fundamental for development and defense because of its inherent advantages for military naval purposes at war. Another striking conclusion is that nuclear power is the best solution for country energy security, more than to avoid climate changes, but to help the nation to resist climate changes. A solution to mitigate the high overnight costs of nuclear power was also proposed. It was demonstrated qualitatively that the adoption of dual purpose mobile nuclear power plants military performances, economic development and risks management.
\end{abstract}

\section{Keywords}

System Engineering, Nuclear Energy, Energy Security, Climate Changes, Constructal Law, PWR

\section{Introduction}

Many works give emphasis on the need of nuclear power to reduce climate change and environmental impacts [1] [2]. The rationale is that nuclear power emits much less greenhouse gases per energy unit than fossil fuels and causes less environmental damage than many renewable power sources. Additionally, nuclear power provides stable generation, unlike many renewable power sources (solar, wind). And nuclear power is relatively cheap.

As a matter of fact, [3] makes a comprehensive survey about estimates of carbon emissions of nuclear power. It is concluded that nuclear cycle greenhouse 
gases emission is much smaller than fossil fuels. [4] demonstrates that, historically, nuclear power reduces carbon emissions.

Some works demonstrate that nuclear power is historically safer (less casualties, health problems and environmental catastrophes) than most power sources [5] [6].

The energy security issue is also a concern. Nuclear power is regarded as a mean to secure energy supply [7] [8]. The reason is that nuclear fuel has stable prices and its compactness allows inexpensive reserves storage.

Shipping is major atmosphere pollution source, being worldly responsible in 2007 for $2.7 \%$ of $\mathrm{CO}_{2}, 4 \%$ to $9 \%$ of SOx and $15 \%$ of $\mathrm{NOx}$ emissions [9]. Nowadays, shipping is responsible by $95 \%$ of global commerce [10] and plays a key role on economy and prosperity.

The contributions of this work are: first, to improve interpretation of society systems by constructal law [11]; second, to propose system engineering methods to analyze society; third, to introduce wars and partner countries downfall, besides climate changes, as design basis risks for energy systems; and last, but not least, to propose an institutional solution to allow rational use of nuclear energy at sea.

Constructal law theory states "for a flow system to persist in time, its configuration must morph such that it provides easier access to its streams" [12]. The organized society is a flow system [12], as it depends on circulation of goods to survive and achieve development.

This work proposes the application of system engineering methods to define vital institutions, seeking development and well-being.

One key factor is to assure better quality of life to people, who tend to leave poor countries and enter richer countries. This strengthens the powerful countries and weakens poor countries. From a constructal law standpoint, better quality of life is a subjective impression caused by improved flows. The state expansion is analogous to a river system formation. A better flow system drains other less efficient systems, making them disappear.

The use of system engineering methods to analyze a country adds value because complex systems usually have counter intuitive behavior. This means common sense probably induces to errors. From constructal law, any policy error leading to any vital flow interruption may cause the system to perish if not corrected in time.

Another key concept is system engineering. According with Wymore [13], a system is a division of the perceived world in two parts: one internal and other external. From the internal part to the external part there are outputs and from external part to internal part there are inputs. System engineering inverts typical engineering practice because it states abstract problems and not solutions [14]. System engineering covers a broad range of subjects on the specification, design and construction of human-made systems [15]. Currently, many authors from different fields propose several methodologies. Some methodologies come from software engineering techniques [16] [17] [18] [19] and others were developed in aerospace applications [20] [21] [22]. A comprehensive survey about the most 
modern system engineering methodologies is presented by [23].

The general objective of this work is to propose the application of system engineering methods to define vital institutions to seek development and well-being (results of improved flows), avoiding pitfalls of common sense. Other objective is to demonstrate that nuclear power is imperative in the energetic matrix of any country. The last objective is to propose system solutions to explore nuclear power.

Chapter 2 presents generic and specific objectives of this work. Chapter 3 presents some assumptions. Chapter 4 presents the method. Chapter 5 develops the core ideas. Chapter 6 presents the solutions found. A discussion of the results is done at Chapter 7. Concluding remarks are made at Chapter 8.

\section{Assumptions}

This work is based on the following assumptions:

- Society vital institutions are tools to improve people lives;

- Economic development is required for improving people lives;

- Society is a complex system;

- System engineering methods are adequate to improve state organization;

- Human society behavior obey natural laws and events may be predicted;

- Constructal law is applicable in human societies once there are flows required for the existence of people and economic activity;

- The main flows in institutions are information (orders, reports and data) and credit (society symbols of expectations on individuals, meaning titles or money). If those flows are disturbed, cooperation between people is terminated. In other words, without recognition, nobody works. Without knowing what to do, nobody works;

- People need food and energy to live;

- State collapses observed throughout history may happen again if proper measures are not taken;

- Most collapses were caused by flows disruptions which prevented people from obtaining basic needs;

- Wars between states are unavoidable and their frequency rises when there is power unbalance between nations;

- Modern states may be regarded as cyber-systems once there are feedback loops in the political power;

- Important needs of a state must be satisfied with well proven solutions, both technical or institutional due reliability issues;

- The financial market is a proven institution; and

- For funds rising, $2 \%$ yearly interest rates (above inflation rates) are assumed. For lending money, $7 \%$ yearly interest rates are assumed.

- The interfaces of a country with the rest of the world are: diplomacy (embassies); commerce (products and services exchanges for profit); armed forces (peaceful or violent contacts between military personnel or industry); media (data exchanges, science exchanges, cultural exchanges, journalists); weather 
(climate phenomena perceived by people).

- The states of a country are: peace; public calamity; under siege; limited war; total war, adapted from [24]. The transitions between them are presented at Figure 1.

- The activity at interfaces of the country, by state, is summarized in Table 1 below.

\section{Method and Development}

System engineering is based on the notion of system, defined as a division of the world in two parts: one internal and other external, with inputs and outputs between the two parts [13]. Initially, the behavior is modelled by states [14]. Assuming its specification is provided, the top-down analysis of the design of a system has the following steps:

-Identification of blocks within the system;

-Identification of service functions of each block;

-Identification of interfaces of each block;

-Identification of states (modes of interaction with other blocks at interfaces);

-Postulation of undesirable events at each interface (risk analysis);

-Identification of required quality for each service function (failure rate and repair rate);

-Identification of constraints (costs, volume, weight, safety and other properties).

\subsection{Country Analysis}

This work proposes the division of a country in the following blocks: Government, which defines policies for all, fund researches and command armed forces;

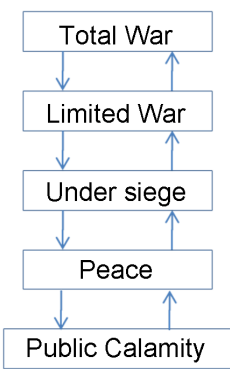

Figure 1. State diagram of a generic country.

Table 1. Activity at interfaces per state.

\begin{tabular}{cccccc}
\hline & Peace & Public Calamity & Under siege & Limited War & Total War \\
\hline Armed forces & $\begin{array}{c}\text { Eventual } \\
\text { Cooperation }\end{array}$ & $\begin{array}{c}\text { Improved } \\
\text { Cooperation }\end{array}$ & Deterrence & $\begin{array}{c}\text { Chirurgical } \\
\text { attacks }\end{array}$ & Invasion \\
Commerce & Free & Free & Restricted & Blocked & Blocked \\
Diplomacy & Active & Active & Very active & Restricted & Inactive \\
Media & Free & Free & Restricted & Manipulated & Blocked \\
Weather & Normal & Calamity & Normal & Normal & Normal \\
\hline
\end{tabular}


research institutions which produce and share knowledge through media; vital functions which enable human life and economic activity for all; and people and companies which exchange goods and services through commerce, pay taxes and provide people to all. In short, modern countries may be regarded as having the blocks and functions shown at Figure 2.

Power sources, transport system and food production/distribution are fundamental to keep people alive and able to engage in economical production activities. Those systems have complex relationships between themselves and it can be stated they perform vital functions because people cannot live without them.

Besides the need of high reliability, those functions need to be provided at low prices, otherwise people require high salaries, which in turn makes economical production expensive. Expensive production in a globalized world means lack of competitiveness, which may turn into bankruptcy, unemployment, poverty and then, political instability.

From constructal law standpoint, unaffordable prices (for vital functions) are streams disruptions. Politicians need to assure no stakeholder is placed in a position which rewards him to disrupt vital streams, like monopoly or trusts.

Vital functions must not be subjected to monopoly because there is not mutual consent-buyers need to pay any price set by sellers, which means the seller is a price setter.

There are two main solutions to assure vital functions are performed at low cost: to keep a vast number of small suppliers in perfect concurrency; or to create non-profit organizations to carry out those tasks. In energy system, which requires large investments, the adoption of non-profit organizations may seem more realistic.

In other words, if vital functions have a dedicated credit line (may be a credit

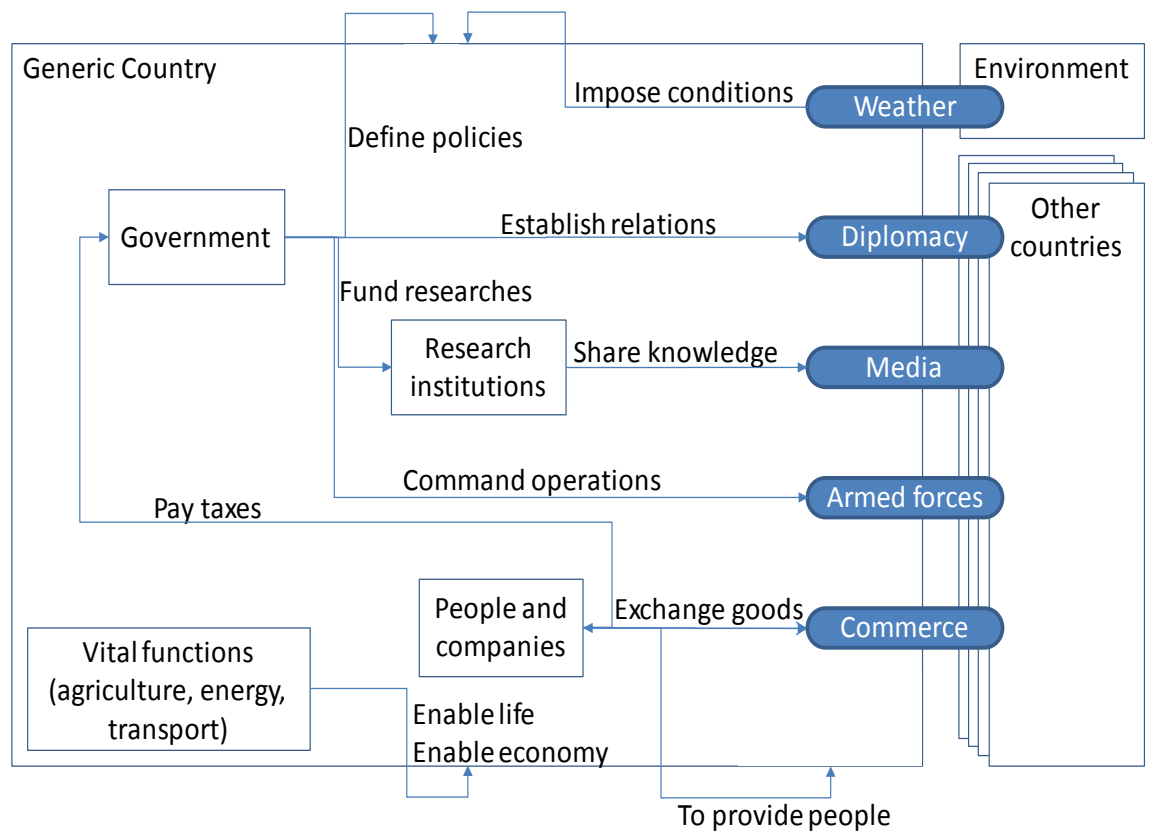

Figure 2. Country block diagram. 
system other than money or profit) they may be provided at production costs. Vital streams at lowest costs (or eased at maximum) maximize economic development. As an example, ancient China employed a system of titles and authority where promotion was based on results at agriculture or at war [25].

On the other hand, vital functions need to be protected from aggressions from other countries when war arrives. The armed forces probably attack the vital functions of the enemies, as it was observed during Second World War.

Due intrinsic characteristics of navies (mobility, permanence on station, flexibility) and the huge volume of maritime transportation (because shipping is cheaper than land transportation), during war the navies usually play the leading role. From constructal point of view, flow of goods and people by the sea receives less resistance than by land.

Some exceptions may appear inside a given continent, like the role played by the Red Army during Second World War. But in conflicts between continents, like in the current globalized world, navy has become the main player amongst the armed forces.

The vital functions and the Navy need to be planned with decades of anticipation because of the current technological level and reliabilities required. As they are vital, care about environmental sustainability is also needed.

Some authors speak of capital costs to analyze options of power sources [26]. However, the need of vital functions is not under question like other consumption goods (i.e. sport cars, washing machines). Consumption goods are usually produced after borrowing capital. This is done like that because it is impossible to foresee innovative technologies and the capital market allows creative people and enterprises supply new products in shorter time. Those goods are produced at risk of the supplier, and if the supplier goes bankrupt, it does not cause major damage to society.

The same is not true for energy production. If a country has problems with power supply, the entire society is endangered. The point here is that vital functions must not be analyzed as non-vital economical activities, comparing alternatives by their profitability or financial aspects. Otherwise people may collectively abandon vital functions and, consequently, collectively perish. On the other hand, it is not under question if the society will or not need power sources: it sure will, and politicians need to provide solutions to convince people to produce energy at low cost.

\subsection{Power Sources Technologies Analysis}

Suppose a country impose by regulations that every power supply institution raises funds in advance to replace current power sources and accommodate expansions. The capital market is then used in a more favorable way and there are capital discounts and not capital costs. Therefore, a country proceeding like this may provide electric power to people at a much lower cost.

It is assumed fuel need to be paid as used, once its price is not predictable, but equipment costs are more predictable. A fund raiser for 60 years at $2 \%$ yearly 
interests achieves prices reduction of $47 \%$, while a fund developed for 30 years at $2 \%$ yearly interests achieves prices reduction of $26 \%$.

The ratio of individual payments of a 30 years life over a 60 years life to rise the same value at $2 \%$ /year interest is $2.81-$ it is almost 3 times more economical to adopt a 60 -year life cycle at $2 \%$ /year interests and for higher interests, this ratio is still bigger. Therefore, environmental impacts should be smaller if a priori interests are adopted once long-lived technologies become cheaper-less plants, less damage.

Overnight costs, fuel costs and operational costs from U.S. Energy Information Administration are presented at Table 2. To complete the analysis, some realistic assumptions are also presented in Table 2, like load factor and plant life. The last two columns of Table 2 show that pre-paid costs (funds raised in advance) makes huge differences in power sources technologies which have high capital costs. This table assumes funding at $2 \%$ /year and lending interests at $7 \% / y e a r$ and a fund is raised during the service life of a given plant. Another fact is that, regardless of technologies, the practice of raising funds in advance cuts down energy consumer costs roughly by half, at least.

However, any power source has availability problems, once not all countries have adequate rivers for hydroelectric production, wind is not constant, domestic reserves of coal, gas and uranium may not be available.

Even not present in every country, uranium is mined in many different countries, or has a better geographic distribution than oil, which is concentrated in middle east. Another factor is the intrinsic power density of the fuel allows the construction of reserves at low cost, allowing time for a country to find new partners in case of loss of imports. Therefore, the best option for a reliable power source for a given country may be nuclear power because of the stability of fuel price [27], long life and overall cost.

Probably, the optimum solution would be a combination of technologies in a proportion to be defined ad hoc for each country, balancing availability and practical issues.

\subsection{Country States Analysis}

Adapted from [24], the occidental countries have shown throughout history

Table 2. Comparison between power sources.

\begin{tabular}{|c|c|c|c|c|c|c|c|}
\hline Type & $\begin{array}{c}\text { Overnight } \\
\text { cost } \\
{[\$ / K W]}\end{array}$ & $\begin{array}{l}\text { Fuel cost } \\
{[\$ / k W h]}\end{array}$ & $\begin{array}{l}\text { Operational } \\
\text { cost } \\
{[\$ / \text { year } / \mathrm{kW}]}\end{array}$ & $\begin{array}{l}\text { Load } \\
\text { factor }\end{array}$ & $\begin{array}{c}\text { Life } \\
\text { [years] }\end{array}$ & $\begin{array}{c}\text { Pos-paid } \\
\text { cost } \\
{[\mathrm{c} \$ / \mathrm{kWh}]}\end{array}$ & $\begin{array}{c}\text { Pre-paid } \\
\text { cost } \\
{[\mathrm{c} \$ / \mathrm{kWh}}\end{array}$ \\
\hline Advanced nuclear & 5530 & 0.00214 & 93.28 & 0.75 & 60 & 6.61 & 2.37 \\
\hline $\begin{array}{c}\text { Gas } \\
\text { (Advanced NGCC with CCS) }\end{array}$ & 2095 & 0.00678 & 31.79 & 0.75 & 30 & 3.40 & 1.95 \\
\hline Coal (with CCS) & 4724 & 0.00951 & 66.43 & 0.75 & 30 & 7.02 & 3.73 \\
\hline Hydroelectric & 3197 & 0 & 14.13 & 0.75 & 90 & 3.01 & 0.41 \\
\hline Wind Farm-Onshore & 2213 & 0 & 39.55 & 0.35 & 20 & 7.43 & 4.26 \\
\hline
\end{tabular}


some behavior states, shown at Figure 1. Peace is in fact a very unusual state where people perceive no external threat and purely seek economic development.

As the country shifts to more aggressive states, mobilization of armed forces become more intensive and economical production start to be reduced, shifting from welfare to warfare. The zenith of this process is reached at total war state [24], when all resources are used to the complete disarmament of the enemy, mostly stopping activities intended to the well-being of population.

The mobilization to reach warring states may be very costly, once economic activity suffers a radical change. Mobilization has inflated costs, especially if there is improvising and modification of many resources to meet new requirements.

After such events, there is also the costs of demobilization, given a huge volume of equipment was produced for the sole purpose of aggression. Once war ends, people may find no use for this equipment and costly discards may take place. Demobilization may be very costly because many means were made just for war and become overnight useless, leading to large scraps. Table 3 shows the use of society functions by state.

It may be stated that a war likely weakens a society, slowing down economic activity and development. Repeated cycles of war states may draw a country in such impoverished situation it becomes an easy target for other countries. From the analysis of Table 3, it may be easily understood why many revolutions happened after a prolonged war time, as it forcibly causes people discontentment.

Therefore, it is interesting to find ways to minimize losses in the transitions between peaceful and warring states. A possible solution is to adopt dual use

Table 3. Required functions performances by state.

\begin{tabular}{|c|c|c|c|c|c|}
\hline Functions & Peace & $\begin{array}{c}\text { Public } \\
\text { Calamity }\end{array}$ & Under siege & Limited War & Total War \\
\hline Impose conditions & Normal weather & Harsh weather & Normal weather* & Normal weather ${ }^{*}$ & Normal weather ${ }^{*}$ \\
\hline Establish relations & For cooperation & For mutual support & For help of allies & For help of allies & For help of allies \\
\hline Command operations & For joint exercises & For public help & For deterrence & To achieve goals & To disarm enemy \\
\hline Share knowledge & Open communication & Open communication & $\begin{array}{l}\text { Little restrictions on } \\
\text { information }\end{array}$ & $\begin{array}{l}\text { Restrictions on } \\
\text { information }\end{array}$ & Severe restrictions \\
\hline Pay taxes & Lowest taxes & Increased taxes & Lowest taxes & Increased taxes & Heavy taxes \\
\hline Provide people & For economic activity & For aid of affected people & \multicolumn{3}{|c|}{ For economic activity In part for military duties Most for military duties } \\
\hline Enable life & $\begin{array}{l}\text { Only for people } \\
\text { (lowest cost) }\end{array}$ & $\begin{array}{l}\text { Adapted to help } \\
\text { (increased cost) }\end{array}$ & $\begin{array}{l}\text { Creating stocks } \\
\text { (inflation) }\end{array}$ & $\begin{array}{l}\text { For armed forces } \\
\text { (big inflation) }\end{array}$ & $\begin{array}{l}\text { For large armed forces } \\
\text { (very big inflation) }\end{array}$ \\
\hline Enable economy & At lowest price & Redirected to affected places & Creating fuel stocks & $\begin{array}{l}\text { For military industry } \\
\quad \text { (big inflation) }\end{array}$ & $\begin{array}{l}\text { Only for military } \\
\text { industry } \\
\text { (very big inflation) }\end{array}$ \\
\hline
\end{tabular}

*It does not mean that at war the weather is always normal. It means only that in general, there is not cumulation of abnormal states. 
equipment (civilian and military) as much as possible. Dual purpose means may be very efficient because they may be used during many states with minimal adaptations and after that they keep their utility, contributing to prosperity.

A concept like that was in place prior industrial revolution, when England had a Navy which provided transport services and military defense. This structure helped England rise above all countries as it had little mobilization costs and the Navy sustained itself, allowing the development of a great navy.

Climate changes also cause similar effects of wars, in a softer way, because population must abandon its economic activities to help an affected region. Although it is softer, politicians need to take it into account because many societies already collapsed due to climate changes.

\subsection{Military Aspects}

For Navy military ships, nuclear power has many advantages, as follows [28]:

- Improved mobility: the huge energy reserve stored in naval reactors allows fleet displacement at full speed for extended periods which is not possible with less compact fossil fuels;

- Great flexibility: replenishment bases and tanker ships are not needed;

- Longer permanence: the huge energy reserve provides capability to keep operations for longer time;

- Superior robustness: a nuclear fleet would have no weak points as the tankers;

- Bigger payload: greater energy compactness frees more space for useful payload. This aspect is employed in aircraft carriers;

- Air independence: nuclear reactions do not need oxygen, allowing submarines longer immersion;

- Discretion: nuclear power plants do not rely on chemical reactions as in diesels and do not liberate heat in atmosphere, which means less noise and heat displayed;

- High power weapons capability: nuclear energy reserve allows use of energy-intense weapons system.

The adoption of nuclear power greatly improves battle capabilities of Navy ships. Historically, this was the reason for the start of development of nuclear power in United States. In a second moment, Admiral Rickover started to develop nuclear power plants for civilian use (Shipping port) to get support of society for Navy nuclear program [29].

Given the capital importance of Navies in the relation between nations, the major players cannot neglect nuclear power development; even excluded the great power of nuclear weapons themselves.

\subsection{Current Globalization Issues}

The advances in transport and communication technologies allowed the phenomenon of economy globalization. On the other hand, people stay attached to their cultures, beliefs and philosophical systems. 
If, in current globalized world, a country falls behind others in terms of economic competitiveness, it will probably suffer political instabilities as large masses of its population becomes unemployed and maybe without means for subsistence (streams become disrupted).

Large masses without means for subsistence easily fall into despair and despair most probably drives people into fighting, aggravating still more the situation. If people can survive long enough in this situation, they tend to adopt other philosophical system, abandoning their original culture. Although there is some psychological pain in abandoning parental culture, most people can do that to survive.

Therefore, it can be considered globalization has turned into a giant arena where there is no place for the less competitive nations. Any country wanting to survive will be forced to adopt good practices to survive, improving its economic power, its military power and its culture.

Modern societies are flow systems formed by a group of people which share some common language, culture, thoughts, rules, values, beliefs and social behavior. Those entities suffer continuous changes and fight continually for expansion and survival. That fight is not only military, but involves all other fields, like economical, ideological, cultural and scientific.

One key factor for survival is the constructal law theorem. Furthermore, to accomplish the vital flows of energy and equipment in a country, adequate credit and information systems are mandatory. People are not going to make efforts if they get no recognition or they may get greater recognition by working at nonvital functions.

The risk of people collectively neglecting work at vital functions must be politicians main concern. Part of his solution for this problem is to reserve specific credit lines only to those who succeeded in realizing vital functions.

\subsection{Resources Sharing Advantages}

During Elizabethan age, the Royal Navy had two functions (commerce and defense) and this propelled England above all other countries. That is, positive synergy between merchant and military allowed supremacy at sea.

More recently, technological advances made merchant fleet very different from Navy fleet, preventing great synergy between merchant ships and Navies.

Historically, all countries developed nuclear energy for use on Navy because nuclear energy for propulsion is a must for military purposes.

As countries develop base infrastructure for exploitation of nuclear energy for military purposes, there may be idle capacity on installations. On the other hand, suppliers and engineers need constant work to keep qualification. [30] states that keeping people working is less expensive than demobilize and remobilize such highly qualified work force.

On the side of merchant ships, the new regulations about emissions increase fossil fuel prices [31]. Source depletion also increase fossil fuel price. Fossil fuel prices fluctuate but nuclear fuel prices are low and stable. Nuclear is an abundant 
energy source, but its use involves complex know how and delicate political issues, making individual investors afraid of the risks of building a nuclear fleet [10].

\subsection{Merchant Ships Market}

In recent years the sizes of merchant ships have grown, arriving at 565,000 dead weight tons for tankers, 171,000 dead weight tons for containership and 365,000 dead weight tons for bulk carriers.

This increase of size is caused by the six tenths law [32], which makes bigger ships more economical. However, ports infrastructures constraints limit the size of ships, constraining the size growth. Currently, Table 4 presents characteristics of the major classes of big merchant ships in terms of dead weight [33] [34] [35].

The most energy intensive classes are of container ships because of their high economical speed. Therefore, they should be the base for sizing the nominal power of a mobile nuclear power plant.

On the other hand, tankers and bulk carriers play a vital role for a given country because they may transport fuel. Once the energy availability comes at a lower cost, their economical speed should increase, approaching the container ships.

It is not certain ships size will further increase in short term because this would require huge infrastructure investments worldwide.

Possible changes in regulations restricting the types of fuel oil may lead to elevation of fuel costs. This has impacts on shipping rates, profitability and uncertainties of the shipping market.

Shipping is a serious matter and environmental issues impose changes. Those changes should be performed with caution, once a vital flow is involved.

\subsection{Country Risk Analysis}

Suppose a fault tree analysis where the top event is the sudden change of the police makers (by violent means or not) of a society (Figure 3). The typical causes for this event are climate changes, wars, civil wars and partner countries downfall. Each of those events may come by an interface of the country with the rest of the world. In the weather interface, climate changes must be assumed as unavoidable, because they may have or not anthropogenic causes.

Civil wars are not analyzed in this work. The reason is their causes are multiple and complex. Yet they frequently have relation with vital flows disruption, this is not always true. Sometimes purely ideological factors cause civil wars, for instance, by introduction of foreign cultural values in disagreement with traditional values.

Table 4. Major merchant ships classes' typical values.

\begin{tabular}{ccc}
\hline Type & Disp. [t] & Shaft power \\
\hline Tanker-VLCC & 280,000 & $25 \mathrm{MW}$ \\
Containership-Post Panamax & 97,000 & $60 \mathrm{MW}$ \\
Bulk Carrier-Capesize & 150,000 & $15 \mathrm{MW}$ \\
\hline
\end{tabular}




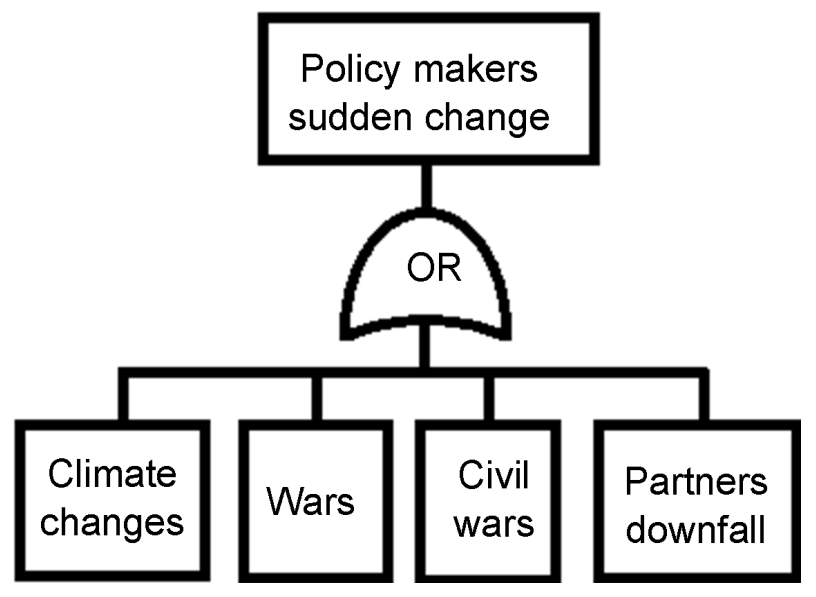

Figure 3. Fault tree analysis.

In the armed forces interface, wars may disrupt logistic lines (road/rail) and realize sea blockade. The absent of some goods, like fuel, food and weapons immobilize a country, forcing surrender. After surrender, the direct killing of the nation leaders may take place. Solutions for transport problems at war include placing main rail/road well inside territory; to have powerful navy to keep sea control; to have long refueling periods for merchant ships. Again, nuclear power may be decisive. Both Navy and large merchant ships become more robust in case of war if nuclear powered.

During wars, people are displaced from farming to fight, reducing food production. Long and improvised logistic lines cause food losses. Farms may be destroyed by enemies. Food prices raises, leading to high inflation rates. Famine is caused by high food prices. Discontentment increases civil war rates. Solutions to keep food production at war time are to keep a large part of population at agriculture; to keep domestic production of essential items; to keep mobilization plans; to give priority to food conservation techniques.

The power sources may also suffer with war. Power plants may be attacked. Fuel supply may suffer disruption. The lack of energy may cause economical collapses and stop weapons production. Besides high inflation rates due lack of energy, there may be deaths by hypothermia in cold countries. Again, discontentment increases civil war rates.

The solutions to achieve energy security at war are to place power plants well inside territory; to have powerful navy to keep sea control; to have large fuel reserves; to have enough domestic fuel production; to keep a balanced geographical distribution of power plants; to design robust power grids well protected inside territory; to have diversity of energy sources; to prioritize small power plants which are more robust to aggressions.

Climate changes also caused political disturbances multiple times within history. Floods or droughts destroyed crops, reducing production. Farmers go bankrupt and stop activities. Food prices rise, driving inflation and famine. Discontentment increases emigration and civil war rates.

The solutions to mitigate climate changes effects in agriculture are to keep the 
largest possible area for agriculture, exporting if needed; to have desalinization means for agriculture to counter draughts; to give farmers subsidies; to provide special credit lines to farmers; to have means for draining in case of floods; to coordinate cultures changes; to import food from many partners. Many renewable power sources must be avoided to keep a large area for food production. Mobile nuclear power plants could be a solution to provide desalinization in case of draughts.

Power sources may also be affected by climate changes. Insulation changes may reduce solar power. Wind changes may damage or reduce wind turbines output. Rain fall changes may damage or reduce hydroelectric output. Crops may be destroyed, reducing production of biofuels. Nuclear, carbon, oil and gas suffer negligible effect from climate changes.

Considering climate changes from a risk analysis approach, the solution is to avoid large use of renewables. The largest shares of energy production should be of nuclear, gas and carbon. Oil should be reserved to portable energy because it cannot be replaced.

In the commerce interface, downfall of strategic partners also may throw a country into chaos. It may cause loss of transport services or loss of source of equipment for transport. This means a country should assure enough domestic production of transport means. Ideally, a country should prioritize use of own transport means.

The effects in food distribution/production are the loss of imported food or loss of imported tools. The solutions to prevent such events are to avoid import of essential food items; to keep domestic production of agriculture tools; to diversify countries from which food is imported.

In the commerce interface, power sources may suffer loss of fuel imports if a collapse occurs in a fuel exporter. The solutions to mitigate this event are to avoid use of domestic energy sources, reserving them to times of need; to have many suppliers; to have diverse of power sources; to stock fuel to keep uninterrupted power supply. The need of stocks benefits nuclear power, given its energy density.

Those types of initiating events (climate changes, wars, civil wars, partner downfall) in this analysis should have their frequencies estimated by country, ad hoc. For instance, the frequency of wars for Brazil and United States are quite different. Without deep history knowledge, or deep statistical analysis, it may be stated that even the most peaceful country has war frequency much bigger than nuclear industry initiating events. Large rupture loss of coolant accidents typically has estimated frequencies smaller than once per ten thousand years per reactor. This period is far more than the longest country duration in history. It is worth mention that accidents in a reactor are localized events which do not affect political stability. While PWR technology never caused a single death (Three Miles Island), each of the country wide events (climate changes, wars, civil wars, partner downfall) in this analysis may cause millions of deaths and political overturn, depending on fault propagation. 
None of those events are currently controllable by a single human authority in the world. Suppose now a hypothetical country which engages war once in ten years. Suppose a system designer needs to make this country frequency of Figure 3 top event be the same as nuclear containment release (once each ten million years). Therefore, a risk reduction factor of one million needs to be achieved. It may not be achievable at all, even without considering other events (climate changes, civil wars, partner downfall).

The problem is that too much money spent in one type of safety may let other risks unmanaged. In other words, the best way to optimize safety is to spend money in uniform way, covering greater risks first.

Small cars may run on battery and electric motors, but trucks and small ships seem to be condemned to use oil and this kind of transport is unavoidable because of its flexibility. So, oil is the only option for small transport in the medium term, so reducing use of oil as much as possible helps to improve overall energy supply reliability. A way to reduce oil consumption is to stop electric power generation by oil. Furthermore, current oil exporters are politically unstable and depending too much on them may be unacceptable risk.

Nuclear energy may only be economical for large ships and electric power plants because it requires a one meter thick radiological shield to protect workers, besides expensive protection systems. Bigger transportation systems like trains and large container ships may employ electrical motors supplied by nuclear energy and be competitive. Besides, nuclear requires little space, allowing construction of inexpensive durable fuel stocks.

Concluding, the best strategy is to have nuclear power to supply big clients (trains, containerships industry) and chemical fuel to supply small clients (trucks, small ships, tractors). Another striking conclusion is that nuclear power is the best solution for country security, not to avoid climate changes, but to help the nation to resist climate changes.

\section{Results and Discussion}

\subsection{Proposal of Business Model}

A solution to both problems could be a joint venture of state and private navigation companies. Non-profit organizations like universities and armed forces may provide development and licensing costs, highly qualified personnel and centralized nuclear waste treatment.

On the other hand, private navigation companies could buy energy for propulsion financing production continuity. The users would not be obliged to have nuclear competencies and any nuclear specific maintenance would be performed by state agencies. As the number of reactors would multiply, it would require series fabrication, which in turn allows dilution of costs.

The same nuclear reactors serving the merchant ships at peace may be called for military service in case of conflict. Once ceased hostilities, the reactors may resume peaceful activities. This mitigates the mobilization and demobilization costs during the transitions of Figure 1. 
In the past, some countries failed to employ nuclear power in merchant ships, but, for instance in the case of NS Savannah, economic considerations were not considered in design.

Current Navy reactors may be too expensive because they are designed for combat only, disregarding economic considerations. So, it cannot be said that nuclear power is not economical without a detailed analysis.

In fact, even for current expensive military reactors, O'Rourke concluded that for large surface combatants, nuclear power could be an economical solution and have better performance.

A compromise between military performances (shock, discretion, reliability) and market requirements (low cost, availability, performance and flexibility) must be obtained.

Besides seagoing purposes, those mobile nuclear power plants could also be employed for electrical power generation for islands or remote areas, further enlarging the market under reach. This would require them to provide electrical power in commercially available standard formats. Figure 4 presents the block diagram of business model.

The state being the owner, it is possible to have a single remote center to supervise the operation of the fleet and to provide emergency means. Emergency means should be available, anywhere on the operation area, on site within a delay of 72 hours. The mobile nuclear power plants cannot be competitive for electric power production at peace time. At war time, however, they may be called to restore power supply following an attack, to power Navy ships (the hulls may be produced faster than nuclear equipment) - they are in fact military resources leased for economical convenience.

As seen in risk analysis section, those mobile nuclear power plants also need to be able to be adapted to desalinization. In climate changes scenarios, when draughts threat food production, they may be deployed to provide fresh water for irrigation. So, they should be adaptable within one month to desalinization.

A series production would start after first units are tested in military ships. Apart the first units being paid by the state, additional units should be paid with funds rose in advance, lowering the energy tariffs.

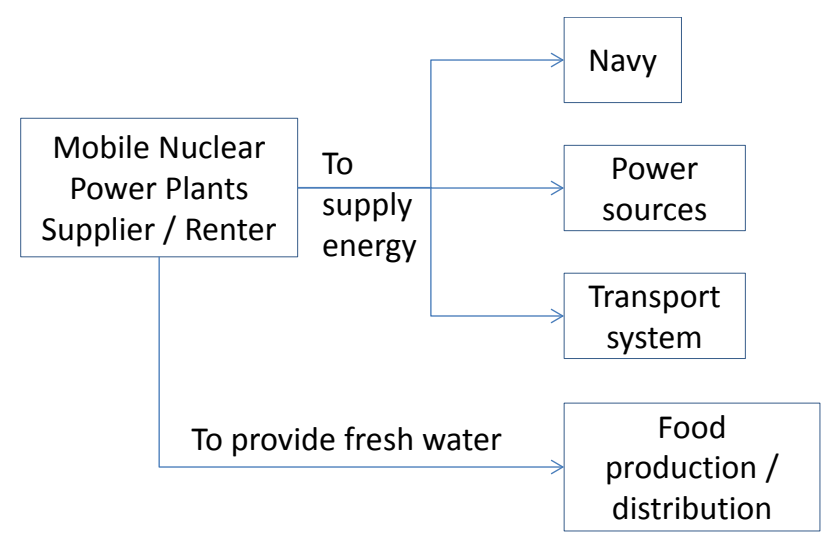

Figure 4. Proposal of business model. 


\subsection{Nuclear Module Requirements}

Therefore, for the medium term, it can be stated a mobile nuclear power plant should have a nominal power of about 70 MWe to provide 60 MWe for shaft line and $10 \mathrm{MWe}$ for auxiliary systems of the ship.

It also should be able to have reduced volume and weight. In a first approach, somewhat like $9000 \mathrm{t}$ and $9000 \mathrm{~m}^{3}$, to be compatible with current propulsion systems and fuel tanks size [36].

The construction cost should be as low as possible, keeping current safety objectives applied to land nuclear power plants.

It should also have competitive operation reliability in comparison with current engines. Graceful degradation is desirable to prevent a ship of being completely helpless at sea.

Nuclear fuel costs should be as low as possible. Once the fabrication of nuclear quality components is expensive and requires longer times, plant lifetime should be if possible, can outlive many ships, which have an average life of 25 years. A life of 60 years is probably attainable.

The overnight costs should be as low as possible to provide energy at low cost. The mobile nuclear power plant should have the level of automation as high as practical, reducing need of nuclear-trained operators and homogenizing procedures.

The nuclear reactor must have a negative temperature coefficient and lower core power densities than previous designs. The mobile nuclear power plant must provide all engineered safety features for the nuclear reactor. The ship does not need to meet nuclear safety, being limited to conventional maritime standards.

The mobile nuclear power plant must comply with EPRI requirements for passive advanced light water reactors (ALWR) [37]. Some major requirements are enumerated as follows:

- It must not rely on active components (large continuously rotating machinery, multiple acting valves, and AC powered divisions) to achieve safe shutdown.

- In the event of loss of the normal power supply, the plant shall have two non-safety-grade sources of AC power. The frequency of event of total loss of $\mathrm{AC}$ power should be limited to $1 \times 10 \mathrm{e}-3$ events per reactor year.

- The annual core damage frequency of the design shall less than or equal to 1 $\times 10 \mathrm{e}-5$ events per reactor year.

- The cumulative frequency is less than $1 \times 10 \mathrm{e}-6$ per reactor year for sequences resulting in greater than 25 rem whole body doses over 24 hours at. 5 -mile from the reactor.

The mobile nuclear power plant must not require human presence, external power sources or any resources from the ship to meet safety objectives.

For refueling, the entire mobile nuclear power plant must be removed and replaced by a refueled one. This way the ship does not need to stop its operation for a long time. It is desirable that the refueling operations match the mainten- 
ance activities of the ship.

Easy detachment of mobile nuclear power plant from ship is desirable to cover nuclear banned ports, as proposed by Gravina [38].

The coupling or decoupling operation should be possible within few hours. A delay of about five hours is thought to be feasible.

A consequence is that this module should have some limited, but reliable, propulsion capacity to be employed in the coupling/decoupling operations. A possible solution could be redundant retractable podded thrusters, as shown at Figure 5.

The mobile nuclear power plant should work in all attitudes and movements experienced by merchant ships during $99 \%$ of their lifetime.

The mobile nuclear power plant must prevent radioactive leakage in case of ship sinking without external help or human intervention. For this, the nuclear containment must be able to resist ship bottoming and collision.

Its power format should be applicable to a wide market, including Navy ships, Merchant ships, Coastal clients, land market, and it should have a commonly used output power format.

To reduce cost, its design, construction and testing should be standardized. The fabrication and functional tests should be completed at factory.

Those plants should limit use of nuclear infrastructure for few operations, ideally for refueling and decommissioning only.

In case of any design basis accident happens at a port, it must cause acceptable radiation exposure, within standard limits for non-nuclear personnel.

From military point of view, it should be as silent as possible. Shock resistance is also required due application in warships.

For the discussion, for instance, if interests are greater than assumed, the long life of nuclear power plants may turn them the most competitive option after hydroelectric source.

A philosophical assumption made is that money and financial market is a tool at hands of state to drive people to adopt good practices. State policies must not

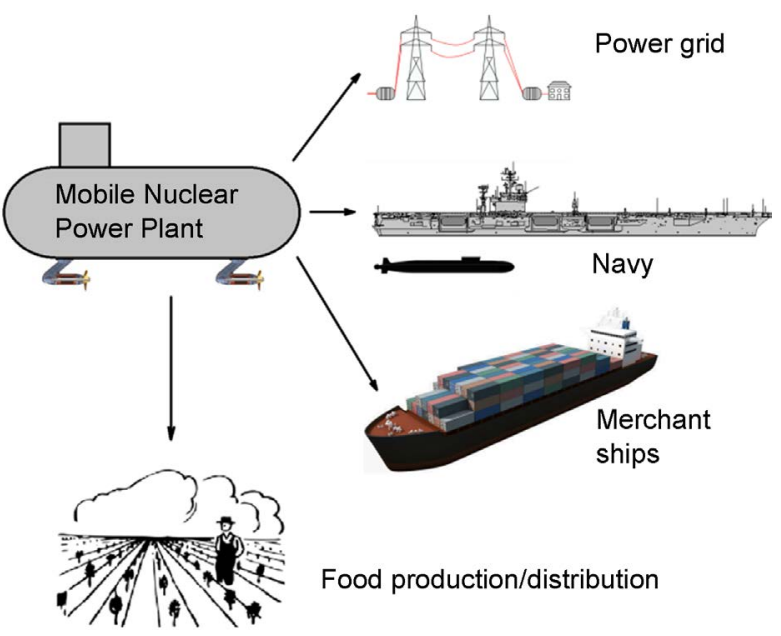

Figure 5. Mobile Nuclear Power Plant clients. 
be driven by financial market, but by political objectives and physical constraints, analyzed by means of system engineering. This approach is justifiable to attain sustainability.

Given the vital importance of energy systems, only known and proved technologies were adopted to reduce technological risks. Again, it is a conservative gamble-a country may obtain a breakthrough technology investing in new power sources, but it is not probable. For now, only PWR is sea proven.

Once military vessels are employed for economic activity at peace time, it is possible to expand navy without heavy burden on taxpayers. The loss in battle worthiness may probably be compensated by bigger numbers and reduction of mobilization costs.

In the worst-case scenario, (it is found impracticable to expand the fleet of mobile nuclear power plants), there would be a cheaper nuclear navy and many country wide risks are mitigated.

In the best-case scenario, the market approves this solution and even allied countries start to buy energy for their merchant fleet, it may be possible to have a self-sustaining navy with overall country industry competitiveness improved. Once a vital service is provided to allies, allied cohesion is also improved.

This work includes also energy power source and transport system besides agriculture as vital functions for the state. This is justified by the fact current technological advances turned people dependent on energy and transport system to obtain food. This is a double-edged sword-for one side, it allowed a bigger population and better comfort level, but the downside is the higher complexity of life support, enhancing the risks.

Another inclusion is the key role of navies, even more important than armies. Now, in a globalized world, armies become much less important, as oceans are going to be the theater of operations.

The nominal power chosen is based on a market analysis of container ships. It was chosen the middle of the range of the biggest numerous class. Although nuclear power could be even better for very large ships, this would restrict the market. Besides that, this power is not too far from the most modern nuclear submarines. Two of them would provide power comparable to aircraft carriers nuclear power plants.

Another aspect is that it may not be possible to have a perfect reuse for every application. So, it is more realistic to make resources sharing as much as possible. For instance, for submarines, it may not be interesting to have a $70 \mathrm{MWe}$ generator, but a turbine directly coupled in the propeller and an auxiliary turbine with a smaller power.

On grounds of the need of proven design for vital functions, it is proposed PWR technology. The only innovation is that it must be passive to resist (with required reliability) for a long time without assistance after a design basis accident. The feasibility of an advanced passive PWR is assumed because of the presence of sea water around the mobile nuclear power plant.

Of course, any emerging reactor technology, compliant with the requirements 
and less expensive or safer, should be considered after it becomes proven.

This work adopted some requirements from [37] which are meant for land based nuclear power plants. Further analysis and the practice may show unforeseen requirements. Because of that, it is first mandatory to validate in military vessels before expanding the fleet to the market.

The postulated events (wars, climate changes and partner countries downfall) were studied as happening separately. However, it is unlikely. It should be interesting to study combinations, like wars caused by climate changes, or wars caused because a critical fuel supplier collapsed. In any case, this would require much more details and should be conducted ad hoc per country.

\section{Conclusion}

This work contributed by demonstrating that application of Constructal law and system engineering techniques allows the perception of counterintuitive facts about society needs. Once some flows are vital and others are not, it is necessary to give separate treatment to some economical functions.

Systems engineering gives the appropriate thinking tools to state problems before seeking solutions to them, managing risks in an integrated way. For politicians, the major risk is society collapse and may be caused by simple negligence of vital functions.

The analysis to choose power sources must adopt a system engineering approach, integrating interfaces and states of the whole country-not only the individual plant profit.

The use of sea is vital for transport, food and energy and navies require nuclear power for military use, which is the main drive for development of nuclear power in past [29]. At the light of climate changes, a country level risk analysis showed that nuclear power must be adopted more to help a country to resist climate changes than to avoid climate changes.

In this work, it was found that wars, climate changes and partner countries downfall are greater risks (more frequent and more severe) than nuclear accidents. Some governments let many vital functions depend on use of imported fossil fuels, making a common mode failure and people tolerate it more than nuclear accidents. Furthermore, politicians waste money in reducing negligible risks at nuclear plants while this resource could improve overall energy security with other measures. In history, there were many revolutions with leaders' assassination due to inflated prices of basic goods and there were no revolutions due to industrial risks or accidents. The proof is accidents of more than 100 deaths (like in coal mines, barrage dams, pipeline failures, nuclear power plant burst) that did not cause political instability. It seems that politicians in some occidental countries are in deadly mistake due to extreme diligence in a technology with local effects and negligence of energy security. If a country adopts a single agency to manage risks, energy security should be improved and nuclear power should become more competitive as it is over regulated and other technologies are under regulated [5]. Other types of energy could become more expensive, 
indeed.

The development of dual purpose mobile nuclear power plants fleet is a solution for construction of a powerful navy within a small budget. This solution has the side effect of lowering energy and transport costs, improving the nation competitiveness. An additional gain is the possibility of use for desalinization, supporting agriculture during possible draughts. At war, they may restore electric power supply after an attack.

A country whose vital functions are performed at low cost is more competitive than countries where vital functions are expensive. In other words, it provides better access for its streams.

Funds may be raised in advance to replace current power plants. In this way, the long lived nuclear power plants become very competitive energy sources. The point is not to find the best power source from financial point of view. The real point is how to obtain the best power sources using available tools.

Transitions between peace and war states become costly if military dedicated technologies are employed. To assure long term prosperity, a country depends on mobilization costs being equal or lower than neighbor countries. In past, dual purpose navy assured England economic competitiveness and military defense prior and during industrial revolution while keeping the mobilization cost at low level. Such concept raised England to the world supremacy status in past and may do the same for any country in future.

If a country has a large nuclear-powered Navy and merchant fleet, if it may enter and exit wars at low costs and if it has strongly bonded allies, then deterrence effect is strong. If deterrence is strong, this country may avoid conflicts and pursue development at full extent. Using environmentally adequate nuclear power, natural resources are kept available for development. Once more developed than others, it naturally attracts more people and investment, becoming populous and rich. Being populous and rich, it may develop superior culture and impose its methods on the world, which means to attain supremacy.

Future work will be to analyze the requirements of components inside the mobile nuclear power plants.

\section{References}

[1] Hong, S.B.C.B.B. (2014) Nuclear Power Can Reduce Emissions and Maintain a Strong Economy: Rating Australia's Optimal Future Electricity-Generation Mix by Technologies and Policies. Applied Energy, 136, 712-725.

[2] Hong, S.B.C.B.B. (2014) South Korean Energy Scenarios Show How Nuclear Power Can Reduce Future Energy and Environmental Costs. Energy Policy, 74, 569-578.

[3] Sovacool, B. (2008) Valuing the Greenhouse Gas Emissions from Nuclear Power: A Critical Survey. Energy Policy, 36, 2950-2963.

[4] Baek, J.P.D. (2014) On the Income-Nuclear Energy- $\mathrm{CO}_{2}$ Emissions Nexus Revisited. Energy Economics, 43, 6-10.

[5] Strupczewski, A. (2003) Accident Risks in Nuclear-Power Plants. Applied Energy, 75, 79-86.

[6] Rashad, S.H.F. (2000) Nuclear Power and the Environment: Comparative Assess- 
ment of Environmental and Health Impacts of Electricity-Generating Systems. Applied Energy, 65, 211-229.

[7] Jun, E.K.W.C.S. (2009) The Analysis of Security Cost for Different Energy Sources. Applied Energy, 86, 1894-1901.

[8] Mari, C. (2014) Hedging Electricity Price Volatility Using Nuclear Power. Applied Energy, 113, 615-621.

[9] Eyring, V.E.A. (2009) Transport Impacts on Atmosphere and Climate: Shipping, Atmospheric Environment. Journal of Atmosphere and Environment, 44, 47354771.

[10] Royal Academy of Engineering (2013) Future Ship Powering Options Exploring Alternative Methods of Ship Propulsion.

[11] Bejan, A.L.S. (2013) Constructal Law of Design and Evolution: Physics, Biology, Technology, and Society. Journal of Applied Physics, 113, Article ID: 151301. https://doi.org/10.1063/1.4798429

[12] Bejan, A.M.G.W. (2007) Constructal Theory of Social Dynamics. Springer, Berlin, 350.

[13] Wymore, A.W. (1967) A Mathematical Theory of Systems Engineering: The Elements. John Wiley \& Sons, New York.

[14] Wymore, A.W. (1993) Model-Based Systems Engineering. CRC Press, Boca Raton.

[15] NASA (2007) NASA Systems Engineering Handbook.

[16] Howard Lykins, S.F.A.M. (2000) Adapting UML for an Object-Oriented Systems Engineering Method. Proceedings of the INCOSE International Symposium, 15-20 July 2000, 490-497.

[17] Long, S.R.C.A.J.E. (1994) A Concurrent Methodology for the System Engineering Design Process. INCOSE International Symposium, August 1994, 226-231.

[18] Cantor, M. (2003) Rational Unified Process ${ }^{\circledast}$ for Systems Engineering, RUP SE Version 2.0. IBM Corporation.

[19] Douglass, B.P. (2005) The Harmony Process. I-Logix, Inc.

[20] Ingham, M.D. (2006) Generating Requirements for Complex Embedded Systems Using State Analysis. Acta Astronautica, 58, 648-661.

[21] Blanchard, B.F.W.J. (2011) System Engineering and Analysis. 5th Edition, Prentice Hall International Series in Industrial and Systems Engineering, Upper Saddle River, 786.

[22] Wasson, C.S. (2006) System Analysis, Design, and Development: Concepts, Principles, and Practices. John Wiley \& Sons, Inc., Hoboken, 832.

[23] Estefan, J.A. (2008) Survey of Model-Based Systems Engineering (MBSE) Methodologies. INCOSE.

[24] Clausewitz, C.V. (1832) On War, Berlin.

[25] Duyvendak, J.J.-L. (1928) The Book of Lord Shang. Éditions Arthur Probsthain, Londres, 346.

[26] U.S. Energy Information Administration (2013) Updated Capital Cost Estimates for Utility Scale Electricity Generating Plants. US Department of Energy, Washington DC.

[27] Eunju Jun, W.K.S.H.C. (2009) The Analysis of Security Cost for Different Energy Sources. Applied Energy, 86, 1894-1901.

[28] O’rourke, R. (2010) Navy Nuclear-Powered Surface Ships: Background, Issues, and Options for Congress. 
[29] Rockwell, T. (2002) The Rickover Effect: How One Man Made a Difference. iUniverse, 486 .

[30] Rand (2007) Sustaining US Nuclear Submarine Design Capabilities.

[31] Lloyd's Register Group Limited (2012) LNG-Fuelled Deep Sea Shipping-The Outlook for LNG Bunker and LNG-Fuelled New-Build Demand up to 2025. Lloyd's Register, London.

[32] Williams Jr, R. (1947) Six-Tenths Factor Aids in Approximating Costs. Chemical Engineering, 54, 124-125.

[33] MAM Diesel A/S (2007) Propulsion Trends in Bulk Carriers. MAM Diesel, Denmark.

[34] MAM Diesel A/S (2009) Propulsion Trends in Container Vessels. MAM Diesel A/S, Denmark.

[35] MAM Diesel A/S (2009) Propulsion Trends in Tankers. MAM Diesel A/S, Denmark.

[36] Uwatoko, K.W.M.S.N. (2007) Considerations for the Global Environment in the Latest Large Container Vessels. Technical Review, 44.

[37] EPRI (1999) Advanced Light Water Reactor Utility Requirements Document, Volume III ALWR Passive Plant. 8th Edition, III, Electric Power Research Institute, Palo Alto.

[38] Gravina, J.E.A. (2012) Concepts for a Modular Nuclear Powered Containership. 17th International Conference on Ships and Shipping Research, Napoli, 17-19 October 2012.

Submit or recommend next manuscript to SCIRP and we will provide best service for you:

Accepting pre-submission inquiries through Email, Facebook, LinkedIn, Twitter, etc.

A wide selection of journals (inclusive of 9 subjects, more than 200 journals)

Providing 24-hour high-quality service

User-friendly online submission system

Fair and swift peer-review system

Efficient typesetting and proofreading procedure

Display of the result of downloads and visits, as well as the number of cited articles

Maximum dissemination of your research work

Submit your manuscript at: http://papersubmission.scirp.org/

Or contact wjnst@scirp.org 